\title{
CD63 e CD123 expressão, autoanticorpos IgG e acurácia do teste do soro autólogo em pacientes com urticária crônica
}

Primeira submissão em 01/05/11 Última submissão em 02/10/11 Aceito para publicação em 24/11/11 Publicado em 20/02/12

\section{CD63 and CD123 expression, IgG autoantibody and accuracy of autologous serum test in patients with chronic urticaria}

Zamir Calamita'; Roseli Nunes da Silveira Antunes²; Odilon Marques de Almeida Filho ${ }^{3}$; Wilson Baleotti Júnior'; Andrea Bronhara Pelá Calamita ${ }^{5}$; Josianne Thomazini Fukasawa ${ }^{6}$; Débora de Aguiar Cavaretto

\begin{abstract}
unitermos
Urticária crônica

Teste cutâneo do soro autólogo

Teste de ativação de basófilo

Acurácia

CD63

CD123

\section{resumo}

Introdução: Na urticária crônica (UC), o teste cutâneo do soro autólogo (TCSA) pode sugerir a etiologia autoimune. Recentemente, uma nova técnica laboratorial denominada teste de ativação de basófilos (TAB) vem sendo utilizada para esse diagnóstico. Objetivos: Analisar o TCSA em relação ao TAB, assim como avaliar os receptores da interleucina 3 (IL3) (CD123) e a presença de autoanticorpos da classe de imunoglobulina $\mathrm{G}(\mathrm{lgC})$ inespecíficos ligados aos basófilos de pacientes com UC. Métodos: Estudamos 33 adultos com UC espontânea com idade média de $42,5+14$ anos. Por meio da citometria de fluxo foi feita a análise da expressão das moléculas $\mathrm{CD} 63$ em basófilos de um doador atópico após o estímulo pelo soro dos pacientes com UC. Também realizamos a pesquisa da expressão da molécula CD123 e de autoanticorpos $\lg G$ inespecíficos. Resultados: O odds ratio (OR) entre o TCSA e o TAB foi de 1 (intervalo de confiança [IC] 95\%: 0,22-4,5). O TCSA para o diagnóstico da UC autoimune mostrou acurácia de $54,5 \%$, sensibilidade de $66 \%$, especificidade de $33 \%$, valor preditivo positivo de $63 \%$ e valor preditivo negativo de $36 \%$. Não houve diferença estatística entre os grupos estudados quanto à média de expressão dos anticorpos lgG inespecíficos e das moléculas CD123 (para um $p<0,05$ ). Discussão: Este estudo demonstrou baixa precisão do TCSA no diagnóstico da UC autoimune; o grupo de pacientes com TCSA positivo não mostrou diferença estatística em relação ao grupo com TCSA negativo nos demais aspectos analisados. Conclusão: Pelos poucos estudos existentes e pela relevância do assunto, acreditamos na necessidade de mais estudos abordando esses aspectos.
\end{abstract}

\section{abstract}

Introduction: The autologous serum skin test (ASST) may suggest an autoimmune etiology in chronic urticaria (CU). A new laboratory technique called basophil activation test (BAT) has been currently employed for its diagnosis. Objective: To analyze ASST in relation to BAT as well as to evaluate interleukin 3 (IL3) receptors (CD123) and non-specific immunoglobulin $G(\mathrm{lg} G)$ autoantibodies bound to basophils in patients with chronic urticaria. Methods: We studied 33 adults with CU and mean age of $42.5+14$ years. After stimulation by serum from patients with CU, CD63 expression on basophils from one atopic donor was analyzed by flow cytometry. Furthermore, we investigated CD123 and IgG autoantibody expressions. Results: The odds ratio (OR) between ASST and BAT was 1.00 (95\% confidence interval [CI]: 0.22 to 4.5). The ASST for autoimmune CU diagnosis showed an accuracy of $54.5 \%$, sensitivity of $66 \%$, specificity of $33 \%$, positive predictive value of $63 \%$, and negative predictive value of $36 \%$. There was no statistical difference between the studied groups as to mean non-specific IgG and CD123 expressions (for a $\mathrm{p}<0.05$ ). Discussion: This study demonstrated that ASST has low accuracy in the diagnosis of autoimmune CU. Concerning other analyzed aspects, there was no statistical difference between positive ASST and negative ASST. Conclusions: Due to insufficient studies in this area and the relevance of this issue, further investigation is required. key words

Chronic urticaria

Autologous serum skin test

Basophil activation test

Accuracy

CD63

CD123

\footnotetext{
1. Médico alergologista imunologista; doutor em Ciências na área de Medicina Interna, Terapêutica e Medicina Baseada em Evidências pela Universidade Federal de São Paulo (UNIFESP); chefe da disciplina de Alergia e Imunologia Clínica da Faculdade de Medicina de Marília (FAMEMA).

2. Hematologista; doutora em Medicina na área de Hematologia pela Universidade de São Paulo (USP); docente da disciplina de Hematologia e chefe do Laboratório de Citometria de Fluxo do Hemocentro da FAMEMA.

3. Farmacêutico bioquímico; doutor em Ciências Biológicas pela Universidade Estadual Paulista (UNESP); chefe da disciplina de Imunologia Básica da FAMEMA.

4. Biomédico; doutor em Ciências Básicas pela Universidade Estadual de Campinas (UNICAMP); chefe do Laboratório de Imuno-Hematologia do Hemocentro da FAMEMA.

5. Dermatologista; docente da disciplina de Dermatologia da FAMEMA.

6. Biomédica; técnica do Laboratório de Citometria de Fluxo do Hemocentro da FAMEMA.

7. Biomédica; técnica do Laboratório de Citometria de Fluxo do Hemocentro da FAMEMA.
} 


\section{Introdução}

A urticária é um quadro clínico dermatológico caracterizado pela formação de pápulas eritematosas frequentemente pruriginosas, isoladas ou agrupadas, em geral fugazes e recorrentes. Essas lesões são decorrentes de vasodilatação e edema da derme e quando esse acometimento ocorre nas regiões mais profundas da pele (tecido subcutâneo e submucoso) denomina-se angioedema, manifestando-se por meio de inchaço, principalmente na face. A urticária e o angioedema são enfermidades comuns que acometem entre $12 \%$ e $22 \%$ dos indivíduos em alguma fase da vida ${ }^{(13)}$.

A urticária é classificada em aguda ou crônica de acordo com a duração da sintomatologia; na forma aguda os sintomas não ultrapassam seis semanas e na forma crônica a duração persiste por mais tempo. A urticária crônica (UC) tem prevalência mundial que varia de $0,27 \%$ a $2,1 \%{ }^{(13)}$.

Denomina-se UC idiopática ou espontânea quando não se descobre uma causa; acredita-se que em torno de $40 \%$ das urticárias ditas idiopáticas são de etiologia autoimu$n e^{(10)}$, decorrente da ação de autoanticorpos da classe de imunoglobulina ( $\mathrm{lg}$ ) G dirigidos contra receptores de alta afinidade da lgE (FceRl) dos mastócitos cutâneos ou contra as lgE ligadas aos mastócitos. Esses autoanticorpos são predominantemente fixadores de complemento das subclasses lgG1 e lgG3, encontrados com frequência nesses casos de UC autoimune ${ }^{(10)}$. A pesquisa desses autoanticorpos, além de cara e trabalhosa, torna-se muitas vezes de pouca utilidade prática, pois a presença dos mesmos nem sempre guarda correlação com a liberação de histamina dos basófilos.

Para os casos suspeitos de etiologia autoimune, foi proposto um teste cutâneo in vivo de fácil realização, denominado teste cutâneo do soro autólogo (TCSA) ${ }^{(18)}$ ou autossoro, que, apesar da ampla variabilidade de sua acurácia ${ }^{(12)}$, tem a praticidade de poder ser utilizado na rotina clínica diária.

Quanto aos testes in vitro, atualmente uma nova técnica laboratorial denominada teste de ativação de basófilos $(T A B)^{(2,3,5)}$, utilizando-se da citometria de fluxo (CF), tem possibilitado demonstrar por meio da expressão de moléculas CD63 que basófilos de doadores atópicos podem ser ativados quando estimulados por soro de pacientes com UC (supostamente de etiologia autoimune). Essa técnica demonstrou significativa correlação com o teste de liberação de histamina (TLH), utilizado até então para confirmar a presença funcional de autoanticorpos em pacientes com UC ${ }^{(9,21)}$.

A detecção de autoanticorpos lgG (inespecíficos), os quais poderiam ter correlação com a presença de anticorpos
IgG contra receptores de alta afinidade para IgE ou contra a própria IgE (ligada aos basófilos), e a relação da interleucina 3 (IL3) na modulação da liberação de histamina dos basófilos ${ }^{(6,16)}$ pelos receptores de IL3 (antígeno CD123) são questões merecedoras de investigação, pois podem trazer conhecimentos importantes para a melhor compreensão da etiopatogenia da UC, tornando esses tópicos também alvos de nossa pesquisa.

Portanto, pela relevância que todos esses aspectos possuem no melhor entendimento e diagnóstico da UC, este trabalho objetivou analisar a relação do TCSA (um teste in vivo) com o $\mathrm{TAB}$ (um teste in vitro), assim como o antígeno CD123 e a pesquisa de autoanticorpos lgG inespecíficos ligados aos basófilos de pacientes com UC.

\section{Métodos}

Participaram deste estudo 33 pacientes adultos com UC espontânea há mais de seis semanas (24 mulheres e nove homens) atendidos no ambulatório de Alergia e Imunologia da Faculdade de Medicina de Marília (FAMEMA) ou em clínica particular de alergia em Marília, cidade situada no centro-oeste do estado de São Paulo. Desses pacientes, 22 apresentavam TCSA positivo e os demais, TCSA negativo.

Foram obtidos história e exame físico detalhado, com ênfase para o uso de medicamentos em geral e características da dieta; casos de possível hipersensibilidade medicamentosa ou alergia alimentar foram excluídos, assim como pacientes com evidência clínica de alguma doença sistêmica subjacente ou urticária física.

Na primeira consulta, os pacientes foram orientados para realizar uma dieta com exclusão de aditivos alimentares, com ênfase para os corantes e conservantes, assim como restringir o uso de anti-inflamatórios não hormonais por um período mínimo de duas semanas; na segunda consulta, eles foram avaliados e só foram incluídos os casos em que houve persistência da urticária apesar dos cuidados tomados.

Foram solicitados para todos os pacientes hemograma, IgE, protoparasitológico (três amostras), hormônio tireoestimulante (TSH), anticorpo antimicrossomal e fator antinúcleo (FAN). De forma particularizada em caso de suspeita de alguma outra patologia associada, também foram solicitados um ou mais dos seguintes exames laboratoriais: creatinina, transaminase glutâmico-oxalacética (TGO), transaminase glutâmico-pirúvica (TGP), velocidade de hemossedimentação (VHS), alfa-1-glicoproteína ácida, 
proteína C reativa, tiroxina livre (FT4), urina 1, endoscopia digestiva alta com pesquisa de Helicobacter pylori, pesquisa de sangue oculto nas fezes e sorologia para hepatites B e $C$, vírus da imunodeficiência humana (HIV), sífilis e Chagas.

Os pacientes foram orientados para deixar de usar qualquer anti-histamínico pelo menos 72 horas antes dos testes in vivo e in vitro, assim como corticoides ou outras drogas que pudessem interferir nos resultados. No caso de corticoides de depósito ou antidepressivos tricíclicos, seria necessário suspender o uso por períodos ainda maiores (de uma semana a um mês).

Participaram deste estudo apenas os pacientes que assinaram o termo de consentimento livremente e após esclarecimento, e o estudo foi aprovado pelo comitê de ética da FAMEMA.

\section{Teste cutâneo do soro autólogo}

Foram obtidos $5 \mathrm{ml}$ de sangue venoso em um tubo vacutainer sem anticoagulante, deixado em temperatura ambiente por 30 minutos, centrifugado a $500 \mathrm{~g}$ por 15 minutos, e em seguida o soro foi separado. Injetou-se $0,05 \mathrm{ml}$ do soro do paciente (autossoro) por via intradérmica (ID). Soro fisiológico $(0,05 \mathrm{ml}, \mathrm{ID})$ foi usado como controle negativo; como controle positivo foi realizada a puntura com histamina $(10 \mathrm{mg} / \mathrm{ml})$. A leitura foi feita após 30 minutos medindo-se a reação local, considerando o resultado positivo quando a pápula produzida pelo soro autólogo tivesse ao menos $1,5 \mathrm{~mm}$ de diâmetro maior que o controle negativo.

\section{Teste de ativação de basófilos, pesquisa de autoanticorpos IgG inespecíficos e do antígeno CD123}

Para avaliar a ativação dos basófilos, utilizamos o kit do BASO-test (Orpegen Pharma, Heidelberg, Alemanha) e a CF. Essa avaliação foi feita por meio da análise da expressão da molécula CD63. O marcador de superfície CD63 (glicoproteína 53), também presente em macrófagos e plaquetas, é em geral expressado fracamente nos basófilos em repouso, porém intensamente nos basófilos ativados. Neste estudo, um único doador foi selecionado por causa da excelente indução do CD63 em seus basófilos. Ele é um doador atópico, com alergia respiratória IgE mediada para ácaros domiciliares e elevação dos níveis séricos totais de $\lg \mathrm{E}$, e pertence ao grupo sanguíneo $\mathrm{O}$ positivo.

Para a realização desse teste, pipetaram-se $100 \mu \mathrm{l}$ de sangue do doador atópico, ao qual foi adicionada uma solução estimulante (IL3), que foi incubada por 10 minutos a $37^{\circ} \mathrm{C}$. A essa solução, foram adicionados $100 \mu \mathrm{l}$ do soro do paciente e o período de incubação foi de 60 minutos a $37^{\circ} \mathrm{C}$ (estímulo para degranulação). A degranulação foi interrompida com o resfriamento no cooler a $0^{\circ} \mathrm{C}$ por 5 minutos e foram adicionados $20 \mu \mathrm{l}$ dos anticorpos monoclonais anti-GP53-FITC e anti-lgE-PE, seguindo-se um período de incubação no cooler a $0^{\circ} \mathrm{C}$ por 20 minutos; foram adicionados $2 \mathrm{ml}$ da solução de lise com incubação de 10 minutos no escuro. Finalmente, lavou-se essa solução com a washing solution (reagente $A$ ), ressuspendendo-a em $400 \mu \mathrm{l}$ de reagente $A$ e, em seguida, feita a aquisição por CF.

Como controle saudável (indivíduos sem urticária), no sentido de estabelecer uma faixa de normalidade de ativação do basófilo, o sangue de quatro voluntários sem urticária serviram como parâmetro, utilizando-se esse soro para estímulo da degranulação dos basófilos com a mesma técnica descrita anteriormente.

A pesquisa de autoanticorpos $\lg G$ inespecíficos ligados aos basófilos dos pacientes com UC foi realizada por CF. Dessa forma, as células foram incubadas com soro teste, posteriormente lavadas com solução fisiológica a $1.800 \mathrm{rpm}$ por 5 minutos e incubadas com um anticorpo secundário, anti-lgG humana de cabra conjugada a FITC (Dako, EUA), por 30 minutos no escuro. Terminada a incubação, as células foram lavadas novamente a $1.800 \mathrm{rpm}$ por 5 minutos e ressuspendidas em $400 \mu \mathrm{l}$ de PBS. A leitura foi feita em citômetro de fluxo FACScalibur (Becton Dickinson) e as amostras foram analisadas na forma de histograma pelo programa CELLQuest. Para pesquisa do antígeno CD123, também utilizamos anticorpo específico marcado e a leitura foi realizada por CF.

\section{Análise estatística}

Os dados com distribuição normal foram expressos por média \pm desvio padrão (DP). Utilizamos o odds ratio (OR) com intervalo de confiança (IC) de $95 \%$ como medida de associação entre o TCSA e o TAB. O teste $t$ de Student foi usado para comparação dos demais dados entre os grupos e o coeficiente de correlação foi considerado significativo quando $p \leq 0,05$.

\section{Resultados}

Foram analisados 33 adultos com UC e idade média de 42,48 anos ( $D P \pm 14,04$ ), dos quais 24 eram mulheres 
(73\%), sendo 22 pacientes com TCSA positivo e $11 \mathrm{com}$ TCSA negativo. As médias de idade (DP) em anos entre os pacientes com TCSA positivo e TCSA negativo foram 40,5 $(14,93)$ e $46,4(11,69)$, respectivamente (Tabela 1).

Os resultados obtidos de forma individualizada para cada paciente estão apresentados na Tabela 2. Considerando-se como parâmetro valores positivos de ativação dos basófilos, aqueles maiores que o valor de 6,78\%, que correspondeu à média de basófilos ativados nos controles normais (pacientes sem urticária) somada a dois DP (média de ativação + $2 \mathrm{DP}$ ), encontramos 21 pacientes com $T A B$ positivo. Destes, 14 tinham TCSA (66,6\%) positivo e sete, TCSA negativo (33,3\%). Entre os 12 pacientes TAB negativos, oito tinham TCSA positivo $(66,6 \%)$ e quatro, TCSA negativo (33,3\%). Entre os 22 pacientes TCSA positivo, 14 tinham TAB positivo $(63,5 \%)$ e oito, TAB negativo $(36,5 \%)$. Tomando-se o OR com IC 95\% como medida de associação entre o TCSA e o TAB, obteríamos, neste estudo, o valor exato de 1 (IC 95\%: 0,22-4,5), portanto, não demonstrando haver diferença estatística entre os grupos. Também não encontramos diferença estatística quando analisadas as médias de ativação de basófilos entre os grupos com TCSA positivo e negativo (para $p \leq 0,05$ ). Considerando-se que o TAB tenha a precisão semelhante ao TLH , portanto, supondo-se que aqui estivesse representando nosso padrão-ouro, e baseando-se na construção de uma tabela $2 \times 2$ (Tabela 3), poderíamos determinar também as seguintes informações a respeito do TCSA em relação ao TAB no diagnóstico da urticária autoimune: sensibilidade de $66,6 \%$, especificidade de $33,3 \%$, valor preditivo positivo de $63,6 \%$, valor preditivo negativo de $36,3 \%$, acurácia de $54,5 \%$ e razão de verossimilhança (positiva e negativa) igual a um.

Comparando-se a média (DP) de expressão de autoanticorpos $\lg G$ inespecíficos nos basófilos dos pacientes com TCSA positivo e TCSA negativo, encontramos respectivamente $635,48(600,59)$ e $677,74(596,08)$, não evidenciando diferença estatística entre os dois grupos (para $p \leq 0,05$ ); o mesmo ocorreu ao compararmos a média (DP) de expressão desses autoanticorpos (lgG) entre os pacientes com TAB positivo $(600,42[513,90])$ e TAB negativo $(729,72[709,84])$.

Também não evidenciamos diferença estatística (para $p \leq 0,05)$ entre a média (DP) de expressão do antígeno CD123 entre os basófilos de pacientes com TAB positivo $(1363,34[569,10])$ e TAB negativo $(1158,38[449,06])$; o mesmo ocorreu ao analisarmos a expressão do CD123 entre o grupo com TCSA positivo $(1209,75[505,31])$ e o com TCSA negativo $(1432,96[567,50])$.

\section{Discussão}

O diagnóstico das reações alérgicas na prática clínica depende principalmente de uma boa história clínica. A complementação diagnóstica, no caso das reações de hipersensibilidade IgE mediada, pode ser realizada em alguns casos por meio de testes cutâneos ou de exames laboratoriais, como a pesquisa de lgE específica, ou outros métodos, como o TLH e o teste de liberação de leucotrie$\operatorname{nos}^{(5)}$, tecnicamente difíceis de serem realizados.

No grupo das doenças alérgicas, a UC ainda é um desafio na prática clínica, em virtude da dificuldade de se demonstrar sua etiologia na maioria dos casos. Os exames complementares em geral pouco ajudam e acredita-se que em torno de $40 \%$ a $50 \%$ dos pacientes previamente diagnosticados como tendo UC idiopática na verdade apresentam um quadro autoimune $\mathrm{e}^{(10,13,18)}$, entretanto sua confirmação diagnóstica ainda é difícil de se realizar.

Como teste in vivo para detecção de autoanticorpos na UC foi estabelecido o TCSA ${ }^{(18)}$. Os investigadores determinaram sensibilidade que variou entre $65 \%$ e $71 \%$ e especificidade em torno de $81 \%$ a $78 \%{ }^{(18)}$. Atualmente, sabemos que o TCSA não é específico para o diagnóstico da UC autoimune e sua precisão é muito variável, de acordo com os diversos estudos já realizados ${ }^{(12)}$, pois ele caracterizaria muito mais uma situação de autorreatividade cutânea. Isso foi admitido pela Academia Europeia de Alergia e Imunologia Clínica que recentemente publicou um consenso ${ }^{(12)}$ a respeito do TCSA na UC (baseando-se na análise de vários estudos já publicados), comparando a resposta do TCSA em pacientes com e sem urticária, assim como analisando-o em função do TLH. Esse consenso observou grande heterogeneidade entre os estudos e concluiu

\section{Características gerais dos pacientes}

Tabela 1 estudados

\begin{tabular}{l|c|c|c|}
\hline $\begin{array}{l}\text { Características } \\
\text { gerais }\end{array}$ & $\begin{array}{c}\text { Pacientes } \\
\text { com urticária }\end{array}$ & $\begin{array}{c}\text { TCSA } \\
\text { positivo }\end{array}$ & $\begin{array}{c}\text { TCSA } \\
\text { negativo }\end{array}$ \\
\hline Número total & 33 & 22 & 11 \\
\hline Idade média & 42,48 & 40,5 & 46,4 \\
\hline (DP) & $(14,04)$ & $(14,93)$ & $(11,69)$ \\
\hline Homens (\%) & $9(27 \%)$ & 6 & 3 \\
\hline Mulheres (\%) & $24(73 \%)$ & 16 & 8 \\
\hline TAB positivo (\%) & $21(64 \%)$ & 14 & 7 \\
\hline TAB negativo (\%) & $12(36 \%)$ & 8 & 4 \\
\hline
\end{tabular}

TCSA: teste cutâneo do soro autólogo; DP: desvio padrão; TAB: teste de ativação de basófilos. 


\section{Tabela 2 Características individuais de cada participante com urticária crônica}

\begin{tabular}{|c|c|c|c|c|c|c|c|}
\hline Paciente & Sexo & $\begin{array}{c}\text { Idade } \\
\text { (em anos) }\end{array}$ & $\begin{array}{l}\text { AA } \\
\text { IgG }\end{array}$ & CD123 & $\begin{array}{c}\text { Ativ. bas. } \\
(\%)\end{array}$ & TAB & TCSA \\
\hline 1 & $\mathrm{~F}$ & 60 & 1329,31 & 919,9 & 12,96 & Pos. & Pos. \\
\hline 2 & M & 54 & 196,98 & 997,11 & 7,93 & Pos. & Pos. \\
\hline 3 & $\mathrm{~F}$ & 54 & 531,11 & 1493,66 & 23,45 & Pos. & Pos. \\
\hline 4 & M & 32 & 411,39 & 883,18 & 23,23 & Pos. & Pos. \\
\hline 5 & M & 42 & 1432,42 & 2672,12 & 16,44 & Pos. & Pos. \\
\hline 6 & M & 50 & 398,96 & 868,2 & 33,57 & Pos. & Pos. \\
\hline 7 & $\mathrm{~F}$ & 18 & 130,6 & 1326,27 & 7,85 & Pos. & Pos. \\
\hline 8 & $\mathrm{~F}$ & 24 & 365,1 & 954,89 & 65,88 & Pos. & Pos. \\
\hline 9 & $\mathrm{~F}$ & 19 & 194,4 & 871,92 & 18,28 & Pos. & Pos. \\
\hline 10 & $\mathrm{~F}$ & 25 & 506,97 & 1508,4 & 56,07 & Pos. & Pos. \\
\hline 11 & M & 36 & 1329,31 & 919,9 & 8,75 & Pos. & Pos. \\
\hline 12 & $\mathrm{~F}$ & 60 & 243,04 & 805,28 & 12,79 & Pos. & Pos. \\
\hline 13 & $\mathrm{~F}$ & 36 & $-^{*}$ & $-^{*}$ & 35,85 & Pos. & Pos. \\
\hline 14 & $\mathrm{~F}$ & 22 & $-^{*}$ & 1552,53 & 19,74 & Pos. & Pos. \\
\hline 15 & $\mathrm{~F}$ & 50 & 349,17 & 1433,8 & 3,9 & Neg. & Pos. \\
\hline 16 & $\mathrm{~F}$ & 34 & 684,57 & 1815,09 & 5,02 & Neg. & Pos. \\
\hline 16 & $\mathrm{~F}$ & 30 & 699,49 & 899,47 & 3,07 & Neg. & Pos. \\
\hline 18 & $\mathrm{~F}$ & 43 & 597,29 & 890,56 & 5,2 & Neg. & Pos. \\
\hline 19 & $\mathrm{~F}$ & 45 & 2561,83 & 995,69 & 4,88 & Neg. & Pos. \\
\hline 20 & $\mathrm{~F}$ & 73 & 203,24 & 2029,12 & 1,99 & Neg. & Pos. \\
\hline 21 & M & 52 & 242,21 & 1095,06 & 1,3 & Neg. & Pos. \\
\hline 22 & $\mathrm{~F}$ & 32 & 302,25 & 472,74 & 2,04 & Neg. & Pos. \\
\hline 23 & M & 57 & 1165,64 & 1845,58 & 36,91 & Pos. & Neg. \\
\hline 24 & M & 54 & 378,34 & 2332,84 & 61,71 & Pos. & Neg. \\
\hline 25 & M & 42 & 292,7 & 2165,59 & 48,9 & Pos. & Neg. \\
\hline 26 & $\mathrm{~F}$ & 63 & 558,91 & 529,36 & 18,74 & Pos. & Neg. \\
\hline 27 & $\mathrm{~F}$ & 39 & 168,07 & 1644,24 & 15,82 & Pos. & Neg. \\
\hline 28 & $\mathrm{~F}$ & 47 & 62,54 & 1591,03 & 16,91 & Pos. & Neg. \\
\hline 29 & $\mathrm{~F}$ & 36 & 1712,29 & 1384,9 & 8,57 & Pos. & Neg. \\
\hline 30 & $\mathrm{~F}$ & 54 & 1733,79 & 1387,97 & 6,04 & Neg. & Neg. \\
\hline 31 & $\mathrm{~F}$ & 26 & 276,15 & 718,16 & 6,05 & Neg. & Neg. \\
\hline 32 & $\mathrm{~F}$ & 58 & 399,82 & 915,16 & 5,13 & Neg. & Neg. \\
\hline 33 & $\mathrm{~F}$ & 35 & 706,94 & 1247,74 & 6,03 & Neg. & Neg. \\
\hline
\end{tabular}

AA IgG: expressão média de autoanticorpos da classe de imunoglobulina G inespecíficos nos basófilos; CD123: expressão média do antígeno CD123 nos basófilos; Ativ. bas.: porcentagem de basófilos ativados; TAB: resultado do teste de ativação de basófilos, podendo ser positivo ou negativo; TCSA: teste cutâneo do soro autólogo, podendo ser positivo ou negativo; Pos.: positivo; Neg.: negativo. *Não avaliável pelo baixo número de eventos.

que o TCSA tem moderada especificidade como marcador da presença de autoanticorpos funcionais, cuja positividade demonstra a existência de fatores circulantes que estimulariam a liberação de mediadores dos mastócitos cutâneos, principalmente histamina, não necessariamente definindo a etiologia autoimune, porém sugerindo-a, visto que entre esses mediadores poderiam estar autoanticorpos específicos para o receptor de alta afinidade para a IgE ou mesmo para 


\section{Tabela $2 \times 2$ para obtenção das}

Tabela 3 características do teste diagnóstico

\begin{tabular}{lc|c|c|}
\hline $\begin{array}{l}\text { Características } \\
\text { dos testes }\end{array}$ & TAB positivo & $\begin{array}{c}\text { TAB } \\
\text { negativo }\end{array}$ & Total \\
\hline TCSA positivo & $\mathrm{a}(14)$ & $\mathrm{b}(8)$ & 22 \\
\hline TCSA negativo & $\mathrm{c} \mathrm{(7)}$ & $\mathrm{d}(4)$ & 11 \\
\hline Total & 21 & 12 & 33 \\
\hline
\end{tabular}

Sensibilidade $=66,6 \%(a / a+c)$; especificidade $=33,3 \%(d / b+d)$; valor preditivo positivo $=63,6 \%(a / a+b)$; valor preditivo negativo $=36,3 \%$ $(d / c+d) ;$ acurácia $=54,5 \%(a+d / a+b+c+d)$.

TAB: teste de ativação de basófilos; TCSA: teste cutâneo do soro autólogo.

a própria IgE, os quais estimulariam a degranulação dos mastócitos cutâneos.

O valor de um teste diagnóstico pode ser obtido comparando-se seus resultados com a presença ou a ausência da doença, por meio da utilização de uma tabela $2 \times 2$, porém, para podermos estimar essas propriedades, deve existir um padrão-ouro para saber se a doença está verdadeiramente presente. O teste considerado padrão-ouro no diagnóstico da UC autoimune seria o TLH, com dosagem de histamina, um teste laboratorial de difícil realização e utilizado apenas em poucos centros de pesquisa. A expressão de marcadores de ativação de basófilos, como CD63 e CD203, realizada por intermédio do TAB e detectada pela CF, tem atraído a atenção dos pesquisadores nos últimos anos, sendo essa técnica laboratorial utilizada para diversas formas de reações alérgicas $^{(2,3,7-9,17,19,21)}$, inclusive UC(22). Por sua significativa correlação com o $\mathrm{TLH}^{(21)}$, propusemos a utilização desse parâmetro como padrão-ouro para a análise da acurácia do TCSA, apesar de sabermos que essa correlação ainda necessitaria melhor comprovação. Levando-se em consideração essas premissas, poderíamos especular que a baixa acurácia do TCSA observada em nossos resultados $(54,5 \%)$ poderia estar relacionada com duas possibilidades principais: (1) nosso padrão-ouro (TAB) não seria adequado (são necessários mais estudos comprovando a estreita correlação entre o TAB e o TLH); (2) o TCSA realmente teria baixa precisão no diagnóstico da UC autoimune. Essa segunda possibilidade dependeria, em primeiro lugar, de uma certeza em relação à primeira asserção, isto é, seria prioritário que o TAB tivesse o status de padrão-ouro para o diagnóstico de UC autoimune. Portanto, para dirimirmos essas dúvidas, seriam necessários mais estudos tanto para comprovar a correlação do TLH com o TAB quanto correlacionar o TCSA com o TAB.

Existem poucos estudos na literatura correlacionando 0 TCSA com o TAB. Em um deles, em uma amostragem de 61 pacientes ${ }^{(3)}$ com UC, foi encontrada correlação significativa da ativação dos basófilos com a positividade do TCSA, diferente do observado em nosso trabalho. Um detalhe que chamou a atenção nesse estudo foi que $69 \%$ dos pacientes tinham queixas compatíveis com urticária de pressão tardia, o que não foi observado em nossa amostragem e que talvez pudesse ser uma variável de interferência nos diferentes resultados entre os dois estudos.

Outro estudo em que foram analisados 29 pacientes com UC, os autores ${ }^{(14)}$ encontraram um aumento da expressão de marcadores de ativação de basófilos (CD63 e CD203c) em ambos os grupos com TCSA positivo e negativo, achado semelhante ao nosso (expressão do CD63). Esse estudo também encontrou maior expressão para o antígeno CD123 nos pacientes com TCSA positivo, diferente do observado em nossa pesquisa, sendo que nesse trabalho, apesar de o número total de pacientes ser semelhante ao nosso, proporcionalmente havia número maior de pacientes com UC e TCSA negativo em relação ao nosso estudo.

Outro ponto que procuramos analisar em nossa pesquisa foi a presença de autoanticorpos $\lg G$ inespecíficos nos basófilos de pacientes com UC. Utilizamos uma metodologia simples e que, caso fosse viável, poderia vir a ter correlação com a presença de autoanticorpos contra receptores específicos de alta afinidade para lgE ou contra a própria IgE ligada aos basófilos. A hipótese inicial era de que essa poderia ser uma maneira mais factível, por meio da qual pudéssemos suspeitar da etiologia autoimune desde que, logicamente complementada pela avaliação clínica, conseguíssemos afastar outras possibilidades diagnósticas (outras doenças autoimunes), em que outros tipos de autoanticorpos pudessem estar ligados aos basófilos. Entretanto, nesta pesquisa, infelizmente não observamos diferença estatística entre os grupos analisados quanto a esse aspecto.

Também em relação à IL3, o fato de esta modular a liberação de histamina dos basófilos, sendo que o aumento da expressão dos receptores de IL3 (antígeno CD123) já foi observado em basófilos de pacientes com TCSA positivo(14), motivou-nos a avaliar essa questão, porém aqui não encontramos diferença estatística (para $p \leq 0,05$ ) em relação à intensidade de expressão dos receptores CD123 entre os grupos analisados. Acreditamos, entretanto, na exigência de mais estudos a esse respeito, inclusive quanto à necessidade de se comparar a expressão do CD123 não só entre os grupos com TCSA positivo e negativo, mas também no grupo de pacientes com UC como um todo, em relação ao grupo-controle saudável, devido a prováveis implicações desse mecanismo na fisiopatogenia da UC. 
O entendimento da patogênese da UC ainda é parcial, necessitando, portanto, de aprofundamento dos estudos, visto que ainda existem muitos aspectos não totalmente esclarecidos. Possível correlação com determinados alelos do antígeno leucocitário humano (HLA), significativa concomitância de doenças da tireoide e/ou autoanticorpos antitireoidianos dirigidos contra a tireoglobulina e a tireoperoxidase (TPO) e anormalidades na função celular dos basófilos são descritos nos pacientes com UC espontânea ${ }^{(11)}$. Recente publicação(1) conseguiu demonstrar correlação etiopatogênica entre distúrbios envolvendo a tireoide e a UC espontânea. Nesse trabalho, os autores comprovaram a existência de autoanticorpos da classe lgE capazes de reagir contra a TPO, produzindo a denominada reação "autoalérgica". Essa autorreação poderia ocorrer contra a TPO circulante originada da própria tireoide (self proteínas) mediada pela ligação cruzada de $\lg \mathrm{E}$, com consequente estimulação e ativação dos mastócitos. Também poderiam existir mecanismos reacionais decorrentes da existência de mimetismo molecular pela semelhança estrutural da TPO proveniente da tireoide com a de outros tecidos como, por exemplo, de eosinófilos ou de patógenos externos, como fungos ${ }^{(1)}$. Outro aspecto seria a possível implicação que a subpopulação de linfócitos T regulatórios (Treg) poderia ter no desencadeamento das doenças alérgicas ${ }^{(15)}$. Evidências indicam importante relação dos linfócitos Treg e das citocinas imunossupressoras (IL10 e fator de transformação do crescimento beta [TGF- $\beta$ ] ) com a manutenção da homeostase da resposta imune, sendo já demonstrada redução na porcentagem dessa subpopulação de linfócitos nos pacientes com UC autoimune ${ }^{(20)}$, o que poderia contribuir com a patogênese da urticária. Historicamente, também é discutida e muito observada na prática clínica a possível correlação do estresse emocional com o desencadeamento e a manutenção da urticária, decorrente da interação do sistema neuroendócrino com o sistema imune. Esse aspecto foi recentemente estudado(4) ${ }^{(4)}$ tilizando-se dosagem sérica do cortisol, fator liberador da corticotrofina (CRF) e hormônio adrenocorticotrófico (ACTH) como parâmetros indicativos da presença de estresse e ativação dos basófilos pela expressão do CD63 pelo TAB. Comparou-se um grupo de 30 pacientes com UC idiopática com outro de 30 pacientes controles normais. Embora os autores não tenham encontrado significativa correlação dos marcadores laboratoriais de estresse com a presença da urticária, observaram tendência de elevação dos níveis séricos do cortisol no grupo com urticária. Também se observou no grupo-controle normal um aumento da resposta in vitro dos basófilos com a presença do CRF e do ACTH, o que não foi visto no grupo com urticária, demonstrando, assim, um desarranjo da normalidade da resposta dos basófilos nos pacientes com urticária.

Em suma, pela importância do assunto e pela necessidade de aprofundamento na elucidação das questões analisadas, torna-se evidente a necessidade de mais estudos abordando não só os aspectos aqui vistos, mas também outros pontos interessantes, como os anteriormente discutidos. Especificamente para os aspectos estudados neste trabalho, poderíamos pontuar os seguintes tópicos merecedores de avaliações futuras:

- corroboração da correlação entre o TAB e o TLH para que o TAB possa ser utilizado como padrão-ouro (de maneira inquestionável) em futuros estudos de teste diagnóstico;

- estabelecimento da acurácia (precisão) do TCSA em relação ao diagnóstico da UC autoimune de forma mais concreta (existe grande heterogeneidade de resultados entre os estudos já realizados);

- comparação da intensidade média de expressão da molécula CD123 entre pacientes com UC e grupo-controle saudável. Entre os pacientes com UC, analisar os subgrupos TAB positivo e TAB negativo, pois esse aspecto pode ter implicações no entendimento da fisiopatogenia da UC.

Em uma perspectiva mais abrangente, também seria interessante avaliar a possível correlação da UC com alterações da subpopulação dos linfócitos Treg, a concomitância de distúrbios da tireoide e a importância do estresse emocional nesse contexto.

\section{Conclusão}

Este estudo não demonstrou associação significativa entre o TCSA e o TAB. Tomando-se como parâmetro o TAB para diagnóstico de UC autoimune, encontramos para o TCSA baixa acurácia. Também não observamos diferença estatística quando comparamos a expressão de autoanticorpos lgG inespecífico e da molécula CD123 entre os grupos de pacientes com TCSA negativo e positivo, assim como entre os grupos com TAB positivo e negativo. Acreditamos que mais estudos abordando esses aspectos serão necessários para que possamos entender melhor a etiopatogenia da UC espontânea e, assim, podermos diagnosticá-la e tratá-la de melhor forma. 


\section{Referências}

1. ALTRICHTER, S. et al. IgE mediated autoallergy against thyroid peroxidase - a novel pathomechanism of chronic spontaneous urticaria? PLOS ONE, v. 6, n. 4, p. e14794, 2011. Disponível em: <http://www.ncbi.nlm. nih.gov/pmc/articles/PMC3075251/pdf/pone.0014794. pdf>. Acesso em: 2 out. 2011.

2. CARRAPATOSO, I.; CADINHA, S.; SANZ, M. L. Aplicação do teste de activação dos basófilos no estudo de reacções de hipersensibilidade a alimentos e fármacos. Rev Port Imunoalergol, v. 13, n. 2, p. 153-64, 2005.

3. DE SWERDT, A. et al. Detection of basophil-activating IgG autoantibodies in chronic idiopathic urticaria by induction of CD63. J Allergy Clin Immunol, v. 116, n. 3, p. 662-7, 2005.

4. DYKE, S. M.; CAREY, B. S.; KAMINSKI, E. R. Effect of stress on basophil function in chronic idiopathic urticaria. Clin Exp Allergy, v. 38, p. 86-92, 2007.

5. EBO, D. G. et al. Basophil activation test by flow cytometry: present and future applications in allergology. Cytometry B Clin Cytom, v. 74B, n. 4, p. 201-10, 2008.

6. FERRER, M.; LUQUIN, E.; KAPLAN, A. P. IL3 effect on basophils histamine release upon stimulation with chronic urticaria sera. Allergy, v. 58, n. 8, p. 802-7, 2003.

7. GAMBOA, P. et al. The flow-cytometric determination of basophil activation induced by aspirin and other nonsteroidal anti-inflammatory drugs (NSAIDs) is useful for in vitro diagnosis of NSAID hypersensitivity syndrome. Clin Exp Allergy, v. 34, n. 9, p. 1448-57, 2004.

8. GAMBOA, P. et al. Use of CD63 expression as a marker of in vitro basophil activation and leukotriene determination in metamizol allergic patients. Allergy, v. 58, n. 4, p. 312-7, 2003.

9. GYIMESI, E. et al. Basophil CD63 expression assay on highly sensitized atopic donor leucocytes - a useful method in chronic autoimmune urticaria. Br J Dermatol, v. 151, n. 2, p. 388-96, 2004.

10. KAPLAN, A. P. Chronic urticaria: pathogenesis and treatment. J Allergy Clin Immunol, v. 114, n. 3, p. 465-74, 2004.

11. KAPLAN, A. P.; GREAVES, M. Pathogenesis of chronic urticaria. Clin Exp Allergy, v. 39, p. 777-87, 2009.
12. KONSTANTINOU, G. N. et al. EAACI/GA²LN task force consensus report: the autologous serum skin test in urticaria. Allergy, v. 64, n. 9, p. 1256-68, 2009.

13. KOZEL, M. M. A.; SABROE, R. A. Chronic urticaria: aetiology, management and current and future treatment options. Drugs, v. 64, n. 22, p. 2515-36, 2004.

14. LOURENÇO, F. D. et al. Activated status of basophils in chronic urticaria leads to interleukin-3 hyperresponsiveness and enhancement of histamine release induced by anti-lgE stimulus. Br J Dermatol, v. 158, n. 5, p. 979-86, 2008.

15. NOURI-ARIA, K. T.; DURHAM, S. R. Regulatory T cells and allergic disease. Inflamm Allergy Drug Targets, v. 7, p. 237-52, 2008.

16. OKAYAMA, Y.; BEGISHVILI, T. B.; CHURCH, M. K. Comparison of mechanisms of IL3 induced histamine release and IL3 priming effect on human basophils. Clin Exp Allergy, v. 23, n. 11, p. 901-10, 1993.

17. RODRIGUES-TRABADO, A. et al. Basophil activation test for the in vitro diagnosis of nonsteroidal antiinflammatory drug hypersensitivity. Allergy Asthma Proc, v. 29, n. 3, p. 241-49, 2008.

18. SABROE, R. A. et al. The autologous serum skin test: a screening test for autoantibodies in chronic idiopathic urticaria. Br J Dermatol, v. 140, n. 3, p. 446-52, 1999.

19. SANZ, M. L.; GAMBOA, P.; DE WECK, A. L. A new combined test with flowcytometric basophil activation and determination of sulfidoleukotrienes is useful for in vitro diagnosis of hypersensitivity to aspirin and other nonsteroidal anti-inflammatory drugs. Int Arch Allergy Immunol, v. 136, n. 1, p. 58-72, 2005.

20. SUN, R. S. et al. Detection of CD4+ CD25+ FOXP3+ regulatory $\mathrm{T}$ cells in peripheral blood of patients with chronic autoimmune urticaria. Australas J Dermatol, v. 52, n. 3, p. e15-8, 2011.

21. SZEGEDI, A. et al. Significant correlation between the CD63 assay and the histamine release assay in chronic urticaria. Br J Dermatol, v. 155, n. 1, p. 67-75, 2006.

22. ZUBERBIER, T. et al. EAACI/GA2LEN/EDF/WAO guideline: definition, classification and diagnosis of urticaria. Allergy, v. 64, p. 1417-26, 2009.

\begin{tabular}{l|l} 
& Endereço para correspondência \\
\hline & Zamir Calamita \\
Av. Monte Carmelo, 800 \\
CEP: 17519-030 - Marilia -SP \\
e-mail: calamita@unimedmarilia.com.br
\end{tabular}

